\title{
Effects of injected or orally ingested opiate drugs on conditioned avoidance response learning in rats
}

\author{
CLINTON L. TRAFTON* \\ Liniversity of Arizona, Tucson, Arizona 85721
}

\begin{abstract}
Groups of rats were given morphine or methadone on a regimen of increasing amounts for 20 days. The animals were then tested using a conditioned avoidance response (CAR) task. Morphine-treated animals tested between 15 min and $3 \mathrm{~h}$ after daily injections were clearly superior to saline-injected control animals. Animals tested following self-regulated oral intake of morphine or methadone and animals tested with $1-\mathrm{min}, 12-\mathrm{h}$, or $24-\mathrm{h}$ delays between daily injections and tests performed very much like control rats. A second experiment was performed which indicated that the superior performance of some groups is associated with drug-induced hyperactivity in animals chronically injected with morphine.
\end{abstract}

Drugs of various types may have easily observable effects on the behavioral capabilities of animals. With opiate drugs, for example, the effect on the behavior of nondependent animals is sometimes one of depression, indexed (in rats) by decreased rates of barpressing (Thompson, Trombley, Luke, \& Lott, 1970) and increased shock avoidance time (Clark \& Samuel, 1969). However, Davis and Brister (1973) have recently shown that single doses of morphine ranging from 1.25 to $20.0 \mathrm{mg} / \mathrm{kg}$ body weight produce hyperactivity for up to $3 \mathrm{~h}$ in rats. Also, since repeated opiate intake is associated with long-term physical dependence and "relapse" tendencies (Wikler \& Pescor, 1970), the withdrawal of opiates from dependent animals can produce extreme behavioral change. Morphine-dependent animals will increase their rates of leverpressing for morphine reward if deprived of the drug or if challenged with an opiate antagonist such as nalorphine. Further, disruption of both avoidance and food-reinforced behavior occurs under conditions of morphine deprivation (Thompson \& Schuster, 1964).

Changes in the maintenance doses of opiate drugs will also cause a marked disruption of task-oriented behaviors of the dependent animal. Such animals are usually given a range of doses and then tested either while the drug intake effect is presumed to be maximal or, in the case of dependent animals, following a period of withdrawal presumed to be most debilitating. However, if drug-dependent animals are given unlimited access to morphine, they do not self-administer large doses following long voluntary periods or withdrawal. On the contrary, they space drug-reinforced barpressing responses over time in such a manner as to establish a rather constant drug-intake level. If concentrations are

*Requests for reprints should be sent to Clinton L. Trafton, Department of Psychology, University of Arizona, Tucson, Arizona 85721. This research was supported in part by Public Health Service Grant 1-R01-MH20971-01. decreased, barpressing increases; if concentrations are increased, barpressing decreases (Weeks \& Collins, 1964). It is not known if opiate-dependent animals would show decreased performance capabilities in standard learning tasks under such conditions of self-regulated opiate intake. The possibility exists that the measured performance decrements in both drug-naive and dependent animals are associated with the extremes of drug level, either too much or none at all. Furthermore, once tolerance has developed in dependent animals, adaptive performance levels might approach those of nondependent animals if drug intake were self-regulated.

The above reasoning presumably approximates the rationale of drug maintenance and substitution programs (methadone) with human opiate addicts. In this case, the patients are transferred from a kind of all-or-none drug intake condition to a minimal-dosage-maintenance program under supervision. Some evidence (Dole, Robinson, Orraca, Towns, Searcy, \& Caine, 1969; McCarrick, 1969) indicates that in such programs, drug-dependent individuals become generally more productive citizens with fewer behavior problems. However, it can be argued that repeated experience with opiate drugs per se is debilitating and that long-term effects of previous drug intake may appear which do not reflect present blood opiate levels. Indeed, Cochin and Kornetsky (1964) have shown persisting tolerance to morphine analgesia and effects on swimming in rats long after blood morphine levels should have been near zero.

The objective of the present research was to study further the conditions under which repeated experience with opiate drugs is associated with learning changes in rats chronically treated with morphine. Specifically, rats are given repeated injections of morphine and then tested in a conditioned avoidance response (CAR) task, with varying delays between injections and tests. Since longer delays produce lowered blood morphine levels, the results should indicate to some extent if chronic morphine intake per se produces behavioral effects or if any effects are primarily related to blood morphine levels at the time of testing. 


\section{EXPERIMENT I}

\section{Method}

\section{Premedication}

Ninety male albino rats.of the Wistar strain were randomly assigned to nine groups. Group 1 received isotonic saline injections (volume $=1.0 \mathrm{cc} / \mathrm{kg}$ ) subcutaneously every $12 \mathrm{~h}$ for a total of 20 days. Groups 2-9 received subcutaneous injections of morphine hydrochloride in isotonic saline solution every $12 \mathrm{~h}$. The morphine concentrations were adjusted so that the rats received $10 \mathrm{mg} / \mathrm{kg}$ in a volume of $1.0 \mathrm{cc} / \mathrm{kg}$ body weight on the first day, $15 \mathrm{mg} / \mathrm{kg}$ on the second day, and so on up to a maximum of $35 \mathrm{mg} / \mathrm{kg}$. Injections were continued for a total of 20 days. Since the rats in Group 2 were to learn to drink a bitter morphine solution in order to self-regulate their drug intake levels during CAR tests, the only drinking solution available to this group during the last 10 days of premedication was a $0.5-\mathrm{mg} / \mathrm{cc}$ morphine solution. If a rat in Group 2 drank less than the amount necessary to obtain $35 \mathrm{mg} / \mathrm{kg}$ of morphine in a 12-h period, the difference was administered via subcutaneous injection. If $35 \mathrm{mg} / \mathrm{kg}$ or more of morphine was ingested, the rat received a needle puncture only. Groups 3-8 received water ad lib throughout the premedication stage. A final group, Group 9, received only a methadone solution $(0.5 \mathrm{mg} / \mathrm{cc})$ to drink during the last 10 days of premedication. Like Group 2, Group 9 rats received injections of varying amounts of morphine depending on whether or not they ingested $35 \mathrm{mg} / \mathrm{kg}$ of methadone during the previous $12 \mathrm{~h}$.

. In summary, six groups (3-8) received increasing amounts of morphine twice daily for 20 days. Group 1 received the same number of injections of saline, and thus constituted a drug-naive control group. Groups 2 and 9 received injections of morphine twice daily, in varying amounts, and during the last 10 days were forced to ingest some or all of their opiate via a drinking solution containing morphine or methadone.

\section{CAR Tests}

Tests were carried out using a two-compartment box with a 2-in.high hurdle separating the two sides. The ends and back of the box were wood with a Plexiglas front and top. The floor consisted of a copper rod grid through which a constant scrambled shock of $0.6 \mathrm{~mA}$ was delivered if the rat failed to respond by jumping over the hurdle within $5 \mathrm{sec}$ following the onset of a buzzer. A $25-W$ bulb located $12 \mathrm{in}$. above the center of the box was on at all times. Each compartment was $10 \mathrm{x}$ 12 in. in size. A two-way avoidance procedure was used such that the buzzer and shock presentations occurred in the compartment occupied by the rat; thus. the animal had to learn to shuttle back and forth. All rats received 20 daily test sessions of five trials each. A 30 -sec intertrial interval was used, and intertrial crossings were not punished. The onset of shock occurred simultaneously with the termination of the $5-\mathrm{sec}$ warning buzzer. The warning buzzer was also terminated when a hurdle cross occurred during the CS period. If the hurdle was not crossed during the CS period (avoidance), the shock grid was electrified until an escape response was emitted. Group 1 received subcutaneous isotonic saline injections once daily $15 \mathrm{~min}$ prior to CAR tests $(1.0 \mathrm{cc} / \mathrm{kg}$ body weight $)$. Group 2 (morphine-drink group) received no morphine via injection during CAR tests but was given needle-only punctures $15 \mathrm{~min}$ prior to daily CAR tests. Group 3 received morphine injections $(35 \mathrm{mg} / \mathrm{kg})$ immediately prior to CAR tests, and Groups 4-8 received morphine injections $15 \mathrm{~min}, 1 \mathrm{~h}, 3 \mathrm{~h}, 12 \mathrm{~h}$, and $24 \mathrm{~h}$ prior to CAR tests. respectively. The amount of morphine injected into Groups $3-8$ was equal to the average amount ingested orally by Group 2 during the 24 -h period preceding $C A R$ tests. Thus. the average amount of morphine ingested by or injected into the rats of Groups 2-8 was constant over a 24-h period, with the delay between injection and CAR tests varied in order to manipuiate the blood-morphine levels at the time of testing. Group 9 reseived needle-only punctures $15 \mathrm{~min}$ prior to CAR tests and received opiates via oral ingestion of methadone solution. However, since oral ingestion is also a less effective route of administration as indexed by analgesic effects, Groups 2 and 9 probably had lower blood morphine levels throughout CAR tests.

This rather unusual technique of morphine administration which is dependent upon the morphine drinking behavior of Group 2 was used in order to parallel, to some extent, the low-dosage maintenance program used with humans (Groups 2 and 9) and to contrast data thus produced with the results of all-or-none intake conditions (Groups 3-8).

In summary, two groups ( 2 and 9 ) received either morphine or methadone via self-regulated oral ingestion. Six groups (3-8) received injections or morphine with injection-test delays of very short (less than $1 \mathrm{~min}$ ) duration to delays of long (24-h) duration. The latter condition of $24 \mathrm{~h}$ between injection and test is the usual "withdrawal" test condition. Group 1 received no drugs at any time. Thus, any group differences in CAR acquisition would presumably reflect differences in delay-induced morphine levels and mode of opiate intake.

\section{Results}

\section{Oral Intake}

Group 2, with only a morphine solution available to drink, and Group 9, with only a methadone solution available, quickly established a stable oral intake pattern during the last 10 premedication days. Both groups typically drank little opiate solution at night and therefore had to be given "booster" shots of morphine in the morning to bring their drug intake to $35 \mathrm{mg} / \mathrm{kg}$ for that $12-h$ period. Subsequently, these animals typically drank a large amount during the day and received puncture-only injections in the evening. On the average, Group 2 (morphine-drink) received $83 \%$ of its daily morphine via oral ingestion, and Group 9 (methadone-drink) received $75 \%$ of its daily opiate via oral ingestion during the last 5 premedication days. During CAR tests. Group 2 drank an average of $38 \mathrm{cc}$ of morphine solution daily. Therefore, the same amount of morphine $(52 \mathrm{mg} / \mathrm{kg}$ average) was injected into rats of Groups 3.8 during CAR tests, an amount less than the $70 \mathrm{mg} / \mathrm{kg}$ given daily during premedication. During CAR tests. Group 9 drank an average of $36 \mathrm{cc}$ of methadone solution daily.

\section{CAR Tests}

The delay between injections and CAR tests is of critical importance in determining the effects of morphine on performance. As Fig. 1 shows, groups tested soon after injections ( $15 \mathrm{~min}$ to $3 \mathrm{~h}$ ) are clearly superior to saline-injected animals in the CAR task. Mann-Whitney U tests (two-tailed) were calculated which compared the average number of avoidance responses for Groups 4. 5, and 6 with the performance of saline-injected control rats (Group 1) during the last 
Fig. 1. Percent correct avoidance responses per five-trial block during 20 test days. Delay between morphine injections and daily tests shown on upper three lines. The other groups received either saline injections or self-regulated oral intake before daily CAR tests.

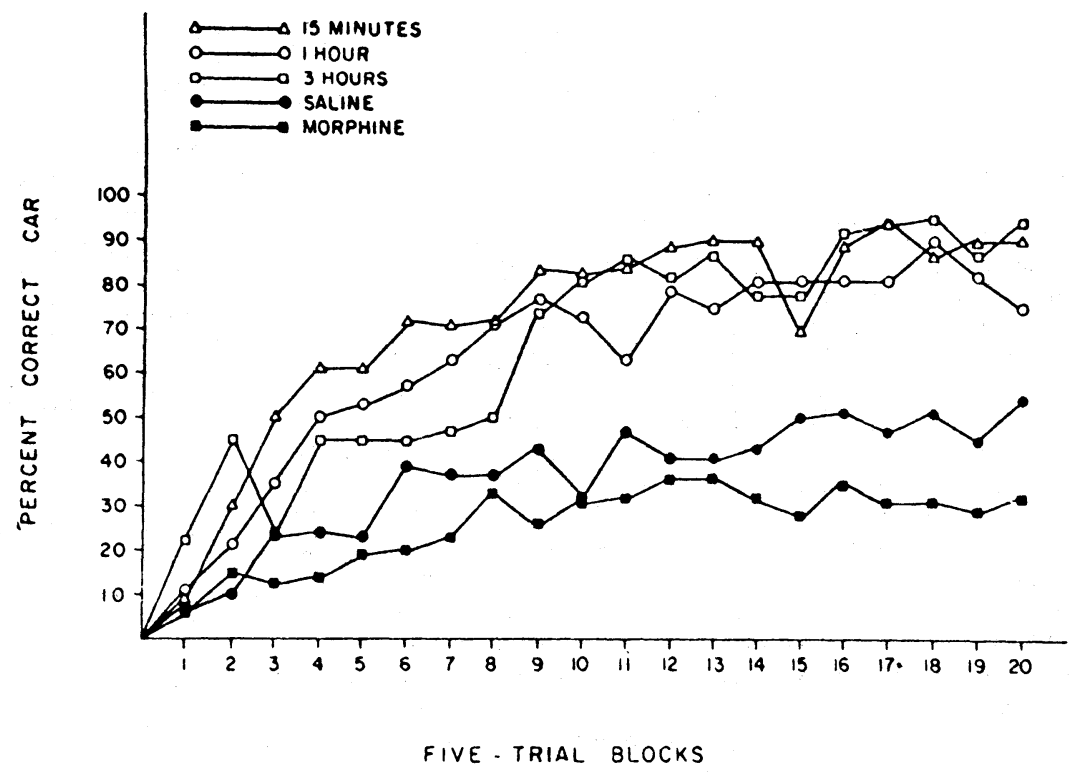

50 trials. Groups 4,5 , and 6 were all significantly better $(p<.01)$ than Group 1 in performing the avoidance task.

The same overall amount of morphine ingested orally and spaced over a 24 -h period prior to CAR tests did not influence CAR performance, although the morphine-drink group (Group 2) did show a tendency toward fewer avoidance responses $(p<.20)$ during the last 50 trials. The no-delay condition (Group 3 ), the 12 or 24-h delay conditions (Groups 7 and 8), and the methadone-drink condition (Group 9) all resulted in performance very much like that associated with saline injections. Therefore, to avoid difficulty of interpretation, the performance of Groups 3, 7, 8, and 9 is not shown in Fig. 1, since these data would simply add four more lines essentially superimposed on the saline-injected group data.

\section{Discussion}

The delay between drug intake and testing, and therefore the blood-morphine levels at the time of testing, determines whether a drug-experienced rat will remain unchanged or perform better on CAR tests relative to nondrugged animals. Animals tested soon $(15 \mathrm{~min}$ to $3 \mathrm{~h})$ after injections when blood-morphine levels are high are better CAR performers than control rats. All other conditions including immediate testing, testing following 12 or $24 \mathrm{~h}$ (withdrawal conditions), and self-maintenance on morphine or methadone solutions result in no change in CAR performance.

The data showing no change if the drug is self-administered in a spaced fashion (Groups 2 and 9) can be interpreted as paralleling the results of human addict drug maintenance and substitution programs. In those programs, deficits in performance are less severe than those presumably associated with the variability on purity and availability of drugs available from illicit sources. However, the rats in the present study were not maintained at extremely high drug levels either during premedication $(70 \mathrm{mg} / \mathrm{kg}$ daily) or during CAR tests $(52 \mathrm{mg} / \mathrm{kg}$ daily). Higher or lower overall drug dosages might cause different relative performance levels.

The absence of any effect in Groups 1, 7, 8, and 9 also runs counter to the notion that repeated opiate experience per se produces behavior changes at some later time of testing. Animals tested immediately after injections and 6,12 , or $24 \mathrm{~h}$ after injections performed like control animals and undoubtedly had low blood-morphine levels at the time of testing. Only Groups 4, 5, and 6 with higher blood-morphine levels performed differently than control rats, and their performance was better.

Rats in Groups 4, 5, and 6 appeared to be hyperactive when they were tested shortly after injections. These groups were also the only ones in which an appreciable number of intertrial crossings were made. Groups 4, 5, and 6 averaged 1.7, 3.0, and 1.4 intertrial crosses per five-trial block, respectively. No other group averaged over 0.2 crosses. Thus, it is possible that the superior performance of these groups is the result of a drug-induced high arousal level. To test this hypothesis, a second experiment was performed. If there is a time-dependent arousal change that influences the CAR performance of chronically drugged rats, activity levels in such rats should be high for several hours after injections and normal at other intervals used.

\section{EXPERIMENT II}

\section{Method}

Twelve additional rats were subjected to the same premedication regimen as those in Groups 3-8 of Experiment $I$. Six rats received subcutaneous injections of morphine twice 
daily with doses increasing to $35 \mathrm{mg} / \mathrm{kg}$ per injection for 20 days. The remaining six rats received saline injections. Each morning, the rats were placed in wire cages mounted on "jiggle" platforms. The cages were $7 \times 7 \times 10$ in. in size, and food and water were available at all times. The movement of the rats on the "jiggle" platform caused a pendulum device to swing, completing a circuit and producing counts which were summed and printed out every $10 \mathrm{~min}$ on a Grason-Stadler Model 1238 printout counter. After the initial $30 \mathrm{~min}$, during which preinjection activity data were collected, the rats were given subcutaneous morphine or saline injections and returned to the "jiggle" platform for 3 more hours. Thus, activity data were collected every $10 \mathrm{~min}$ throughout a $3 \frac{1}{2} 2$-h period daily. The rats received their second daily injection in the evenings, but no activity measures were taken. After 20 days, shots were given only once daily following the initial $30 \mathrm{~min}$ of baseline activity, and the daily amount of morphine injected was decreased from 70 to $52 \mathrm{mg} / \mathrm{kg}$ in order to parallel the drug conditions during the CAR tests in Experiment I. Also, activity data were collected during the 12th hour following injections on Days 21-40. Since the "jiggle" platforms could not be calibrated but did remain at a constant sensitivity level, the average number of counts produced by naive, nondrugged animals during a $60-\mathrm{min}$ period was arbitrarily set equal to 100 . Thus, data collected on a less sensitive platform could be compared with data collected on other platforms. A given rat was always placed on the same platform so that changes before and after injections could be analyzed across the 40 days of tests.

\section{Results}

Over the entire 40-day test period, rats given daily injections of morphine showed increasing activity rates during the first $3 \mathrm{~h}$ following injections. As Fig. 2 (upper) shows, the activity rates were much higher ( $p<.001$, Mann-Whitney two-tailed tests) during the first, second, or third hours following injections over the last 15 test days. The average activity level for these three periods over the last 15 days was 227 counts per hour. The preinjection period produced an average activity rate of 124 counts per hour during the same period. Activity rates during the 12th hour following injections were not significantly different from preinjection period activity rates, averaging 91 counts per hour during the last 15 days. The preinjection period rates, which are measured approximately $24 \mathrm{~h}$ after the last injection, are also quite close to baseline rates. Saline injections were never associated with significant activity rate changes as shown in Fig. 2 (lower). Thus, rats that received several weeks of repeated daily morphine injections of increasing dosage displayed hyperactivity for a period of at least $3 \mathrm{~h}$ following the injections. The hyperactivity appeared during the third or fourth week and continued throughout the experiment. Hyperactivity was not seen 12 or $24 \mathrm{~h}$ (preinjection period) after injections or as a result of saline injections.

\section{DISCUSSION}

After repeated daily morphine injections, no CAR learning deficits were measured in Experiment I. On the contrary, animals tested between $15 \mathrm{~min}$ and $3 \mathrm{~h}$ following daily injections showed clearly better CAR

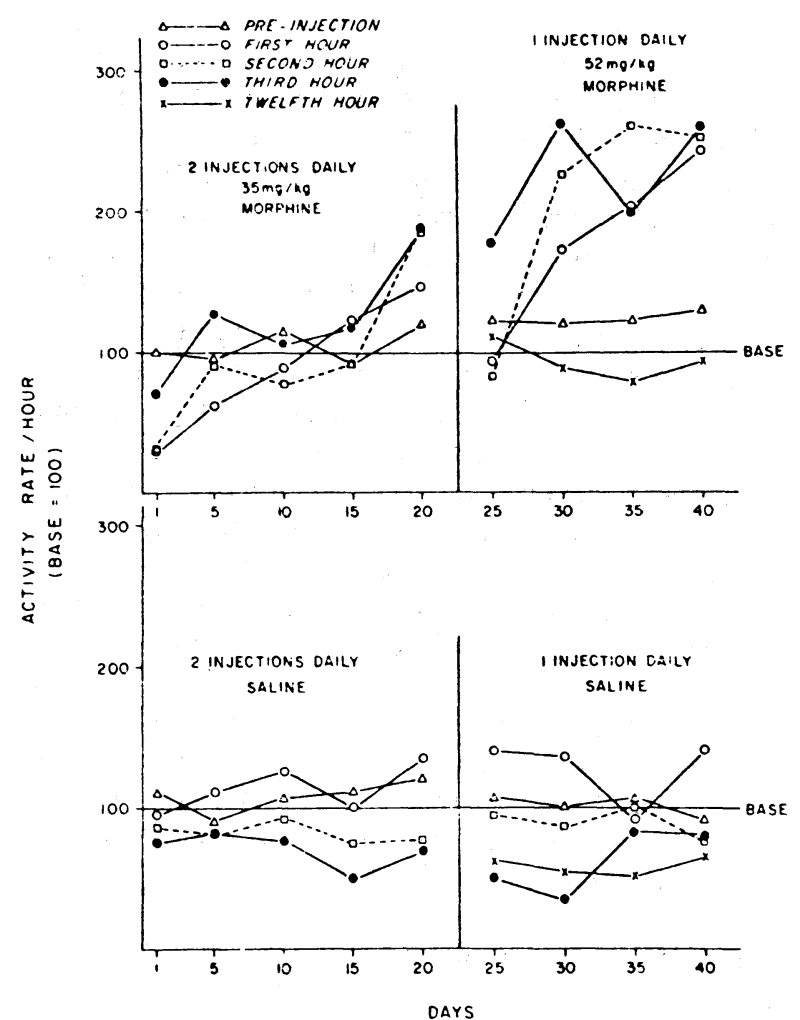

Fig. 2. (Upper) Activity rates during a preinjection period and during the 1st, 2nd, 3rd, and 12th hours following 40 daily morphine injections. (Lower) Activity rates during a preinjection period and during the 1 st, 2 nd, 3rd, and 12 th hours following 40 daily saline injections.

performance. Animals allowed to space their morphine or methadone intake via oral ingestion, animals tested immediately after injections, and animals tested either 12 or $24 \mathrm{~h}$ after injections showed CAR performance patterns very much like saline-injected animals.

Activity rates are higher during the first $3 \mathrm{~h}$ following injections, but only after an animal has received daily injections of morphine for several weeks. Activity rates, measured 12 or $24 \mathrm{~h}$ after injections, remained unchanged relative to the activity levels of saline-injected rats. It seems reasonable, therefore, that the better CAR performance shown in Experiment I by groups tested soon after injections was because of drug-induced hyperactivity. On Day 1 , the rats given $10-\mathrm{mg} / \mathrm{kg}$ injections of morphine were less active $(p<.05)$ during the second and third hours following shots relative to preinjection activity levels. This result is contrary to Davis and Brister's (1973) finding of increased locomotor activity during the same time period. This discrepancy remains unexplained.

Other studies (Cook \& Weidley, 1957; Clark \& Samuel, 1969) have shown decrements in shock avoidance behavior following morphine injections. The major difference between those studies and the present one is that of acute vs chronic injections. Chronically injected rats are, usually, hyperactive and good active 
CAR learners, whereas rats injected only once showed depressed activity and poor CAR performance. Koffer and Coulson (1971) present results consistent with this conclusion. Herman, Freeman, and Ray (1972) have reported similar results as well. The later study involved lower doses $(5,10$, and $20 \mathrm{mg} / \mathrm{kg})$ and fewer injections (13), but is in agreement with the present study. Morphine injections of 10 or $20 \mathrm{mg} / \mathrm{kg}$ initially decreased previously learned avoidance responding, but after several days of repeated injections, performance returned to near-perfect levels. Their rats also showed increasing activity levels over the 13 test days following morphine injections. But it should be noted again that Davis and Brister (1973) report increased activity following a single dose of morphine in several amounts.

The results indicate that conclusions based on the effects of acute administration of an opiate drug cannot be safely generalized to situations involving chronic drug intake. A reversal of performance changes may be seen after repeated drug intake relative to that seen following early experience with opiates. Such was the case in the study by Herman et al (1972), as well as in the present research.

The questions of tolerance and opiate dependence remain unclear in the present research. No independent measures of tolerance or dependence were taken, but it is safe to say that activity patterns clearly changed as a function of chronic morphine intake and that these changes in activity are nicely related to observed CAR performance.

\section{REFERENCES}

Clark, R., \& Samuel, G. K. Drug effects on a discrete conditioned avoidance response in dogs, rhesus monkeys and rats. Psychopharmacologia, 1969, 14, 106-114.

Cochin, J., \& Kornetsky, C. Development and loss of tolerance to morphine in the rat after single and multiple injections. Journal of Pharmacology \& Experimental Therapeutics, 1964, $145,1-10$.

Cook, L., \& Weidley, E. Behavioral effects of some pharmacological agents. Annals of the New York Academy of Sciences, 1957, 66, 740-752.

Davis, W. M., \& Brister, C. C. Acute effects of narcotic analgesics on behavioral arousal in the rat. Journal of Pharmaceutical Sciences, 1973, 62, 974-979.

Dole, V. P., Robinson, J. W., Orraca, J., Towns, E., Searcy, P., \& Caine, E. Methadone treatment of randomly selected criminal addicts. New England Journal of Medicine, 1969, 280, 1372-1375.

Herman, S. J., Freeman, B. J., \& Ray, O. S. The effects of multiple injections of morphine sulfate on shuttle-box behavior in the rat. Psychopharmacologia, 1972, 26, 146-154.

Koffer, K., \& Cowlson, G. E. Effects of chronic and acute morphine administration on one-way avoidance training. Psychonomic Science, 1971, 23, 47-48.

McCarrick, H. A city that has controlled heroin addiction. Nursing Times, 1969, 65, 945-946.

Thompson, T., \& Schuster, C. R. Morphine self-administration, food-reinforced, and avoidance behaviors in rhesus monkeys. Psychopharmacologia, 1964, 5, 87-94.

Thompson, T., Trombley, J., Luke, D., \& Lott, D. Effects of morphine on behavior maintained by four simple food-reinforcement schedules. Psychopharmacologia, 1970, $17,182-192$.

Weeks, J. R., \& Collins, R. J. Factors affecting voluntary morphine intake in self-maintained addicted rats. Psychopharmacologia, 1964, 6, 267-279.

Wikler, A., \& Pescor, F. T. Persistence of "relapse-tendencies" of rats previously made physically dependent on morphine. Psychopharmacologia, 1970, 16, 375-384.

(Received for publication August 27, 1973; accepted September 10, 1973.) 